\title{
Antimicrobial activities of some herbal anti-infectives manufactured and marketed in South-East Nigeria
}

\author{
Ujam Nonye T. ${ }^{1}$, Oli Angus N. ${ }^{1 *}$, Uzodinma Samuel U. ${ }^{2}$, Ikegbunam Moses N. ${ }^{1}$, Anagu Linda \\ O. ${ }^{1}$, Adikwu Michael U. ${ }^{3}$ and Esimone Charles $0 .{ }^{1}$ \\ ${ }^{1}$ Department of Pharmaceutical Microbiology and Biotechnology, Faculty of Pharmaceutical Sciences, Nnamdi Azikiwe \\ University, Agulu Campus, Nigeria. \\ ${ }^{2}$ Department of Clinical Pharmacy and Pharmacy Management, Faculty of Pharmaceutical Sciences, Nnamdi Azikiwe \\ University, Agulu Campus, Nigeria. \\ ${ }^{3}$ Department of Pharmaceutics, Faculty of Pharmaceutical Sciences, University of Nigeria, Nsukka, Nigeria.
}

Accepted 4 June, 2013

\begin{abstract}
The aim of this study was to evaluate the anti-microbial activities of some liquid herbal anti-infectives manufactured and marketed in South-Eastern Nigeria and determine the extent of their microbial contamination. Twenty samples were randomly collected from herbal shops in the five states that make up the South-East Nigeria. Antibacterial activities of the herbal preparations were evaluated using agarwell-diffusion method. The samples that showed significant antibacterial activity against the test organisms were further subjected to cell killing rate test. Maximum inhibitory dilutions of the active compounds were obtained and their in vitro anti-infective activity against multidrug resistance Staphylococcus aureus (MRSA) and Extended Spectrum $\beta$-Lactamase (ESBL) organisms were evaluated also. Eight (40\%) of the product showed some antibacterial activity and none have antifungal activity against the test fungi. Kill kinetic experiment showed that some products have some activity against the test bacteria. One of the products showed antibacterial activity against MRSA. Comparison of the antibacterial activity of the products and conventional antibiotics showed that there was no significant difference among the microorganism to the antibiotics $(F=0.498, P=0.686)$ and herbal antiinfectives $(F=0.477, P=0.700)$. Only $40 \%$ of the 20 products have some antibacterial activity but none have anti-fungal activity. All were heavily contaminated with microorganisms. Current good manufacturing practice may not have been applied in their manufacture.
\end{abstract}

Key words: Herbal anti-infectives, antibacterial activity, South-East Nigeria, liquid preparations.

\section{INTRODUCTION}

Health for all is a dream and a goal which humanity at large shares and strives for but is clear that modern pharmaceuticals are and will remain out of reach for a large proportion of the human population for the foreseeable future (Mosihuzzaman and Choudary, 2008). This gap has created the need for the use of alternative and traditional medicines, largely herbal in nature, to solve human health need. Alternative medicines, such as herbal medicines, are gaining popularity because of typically low side-effect profiles (Wilt et al., 2000), low cost (Vanderhoof, 2001), and a high level of acceptance by patients. Some managed care organizations now offer these therapies as an expanded benefit (Langyan and Ahuja, 2005). In Africa, traditional medicine has always been a part of the culture even though this form of medicine is not as well organized as, for example, in India and China (Ogunshe et al., 2006). Herbal medicine has become a popular form of healthcare at least in African and Asian countries being intertwined with modern medicine (Eisenberg et al., 1998; Esimone et al., 
2002). The use of herbal medicine has always been part of human culture, as some plants possess important therapeutic properties (Barkatullah et al., 2013; Selim et al., 2013). The ideas that certain plants had healing potentials and contain antimicrobial principles were well accepted long before mankind discovered the existence of microbes (Rios and Recio, 2005). Traditional herbalists in Nigeria use various herbal preparations to treat various types of ailments, including diarrhea, urinary tract infections, typhoid fever and skin diseases (Sofowora, 1993).

In developing countries, "traditional medical practice is often viewed as an integral part of their culture" (Kunle et al., 2012; Evans, 1996), traditional medical practice is often viewed as an integral part of their culture. Although it is generally believed that most herbal preparations are safe for consumption, some herbs contain biologically active substances that can be toxic or at least have undesirable side effects (Evans, 1996). There is no effective machinery to regulate manufacturing practices and quality standards (Kunle et al., 2012). Given the variable nature of products of plant origin, ensuring consistent quality of their products is vital for the survival and success of the industry (Bauer, 1998). In Nigeria, there appears to be an overwhelming increase in the public awareness and usage of herbal medical products in the treatments and/or prevention of diseases (Okunlola et al., 2007). With this increased usage, the safety, efficacy and quality of these medicines have been an important concern for health authorities and health professionals (Oluyege and Adelabu, 2010). Many of these products have bogus claims on their labels and these claims may have also led to the increase usage of the products. Advertising in various forms by the herbal practitioners is unparalleled in Nigeria. People now attend hospitals as often as they go to herbalists (Okunade, 2001).

This study was therefore meant to examine the antibacterial properties of some liquid herbal antiinfectives produced and marketed in South-East Nigeria and to estimate their level of contamination.

\section{MATERIALS AND METHODS}

The materials used include: nutrient agar media (Lab M, UK), MacConkey agar, (Fluka, UK), Xylose Lysine Deoxycholate Agar, Urease broth, Citrate agar, Saubouraud Dextrose agar (BIOTECH Laboratories LTD, UK), Mueller Hinton agar media (Oxoid, UK) and Peptone water. All the media were prepared aseptically following the manufacturers' instructions.

\section{Study area}

The study sampled herbal anti-infectives from South-Eastern Nigeria, West Africa. South-Eastern Nigeria comprises five states which include: Abia, Anambra, Ebonyi, Enugu and Imo states.

\section{Samples collection}

A total of twenty (20) different liquid herbal anti-infectives were purchased randomly from identified herbal shops and retail outlets across the South-Eastern states of Nigeria. The samples as shown in Table 1 were kept at room temperature $\left(28 \pm 2^{\circ} \mathrm{C}\right)$ and used within two weeks of collection.

\section{Test organisms}

The microbial cultures were untyped clinical isolates of Staphylococcus aureus, Escherichia coli, Pseudomonas aeruginosa, Salmonella typhi and Candida albicans obtained from the Medical Microbiology Laboratory of Nnamdi Azikiwe University Teaching Hospital, Nnewi. They were properly identified and preserved on agar slants at $37^{\circ} \mathrm{C}$ as stock.

\section{Identification and characterization of the bacteria isolates}

Wire-loopful quantities of the products were stricken onto MacConkey agar, Blood agar, and Sabouraud agar. The plates, incubated aerobically at $37^{\circ} \mathrm{C}$ for 24 to $48 \mathrm{~h}$, were examined for growth and biochemical tests carried out according to the methods described by Monica (2002) for proper identification of the organisms isolated.

\section{Agar well diffusion method}

About $0.1 \mathrm{ml}$ of 0.5 Mcfarland standards of clinical isolates of $S$. aureus, E. coli, $P$. aeruginosa, $S$. typhi and $C$. albicans was taken and aseptically transferred into labeled sterile Petri dishes. Then 20 $\mathrm{ml}$ of molten sterile nutrient agar was poured into the seeded Petri dishes and swirled to distribute the medium homogenously. After solidification, holes of dept $3.5 \mathrm{~mm}$ were made aseptically with a 6 $\mathrm{mm}$ sterile cork borer and sealed. The stock and 2 fold dilution of the liquid herbal products (volume $=0.1 \mathrm{ml}$ ) were introduced into separate wells and allowed to diffuse into the medium. The whole set up was then incubated aerobically for 18 to $24 \mathrm{~h}$ at $37^{\circ} \mathrm{C}$. One well containing sterile water served as control and another containing amoxicillin/clavulanic acid (AMC, 20/10 $\mu \mathrm{g}$ ) served as a positive control in each plate. The antimicrobial activity of the various agents was determined by measurement of the inhibition zone diameter using a meter rule and compared with the control well (containing water).

\section{Determination of ant-bactericidal activity of the herbal anti- infectives using kill kinetic method}

Nutrient broth of volume $(5 \mathrm{ml})$ was dispensed into six culture tubes provided for each indicator bacteria and was sterilized. These were labeled 0 to $5 \mathrm{~h}$ where $0 \mathrm{~h}$ serves as control. One milliliter of four different herbal anti-infectives (product 2, 3, 7, 11) that showed significant antibacterial activity by the agar diffusion method were added to the culture tubes containing the indicator bacteria. The suspension of the indicator bacteria and herbal medicine were thoroughly mixed and held at room temperature $\left(28 \pm 2^{\circ} \mathrm{C}\right)$. Antibactericidal activity was determined by plating $0.1 \mathrm{ml}$ of the suspension at hourly interval for up to $5 \mathrm{~h}$. The plates were incubated and the colony forming units were counted

\section{Determination of maximum inhibitory dilution (MID)}

The MID of the aqueous herbal preparations which showed by the micro-broth dilution method. Serial dilutions of herbal anti-infectives in dilutions of $5: 0,4: 1,3: 2,2: 3,1: 4$ and $0: 5$ of the broth and herbal products, respectively were prepared in sterile test tubes. Standard 
Table 1. Some brands of herbal anti-infectives marketed in South-East Nigeria.

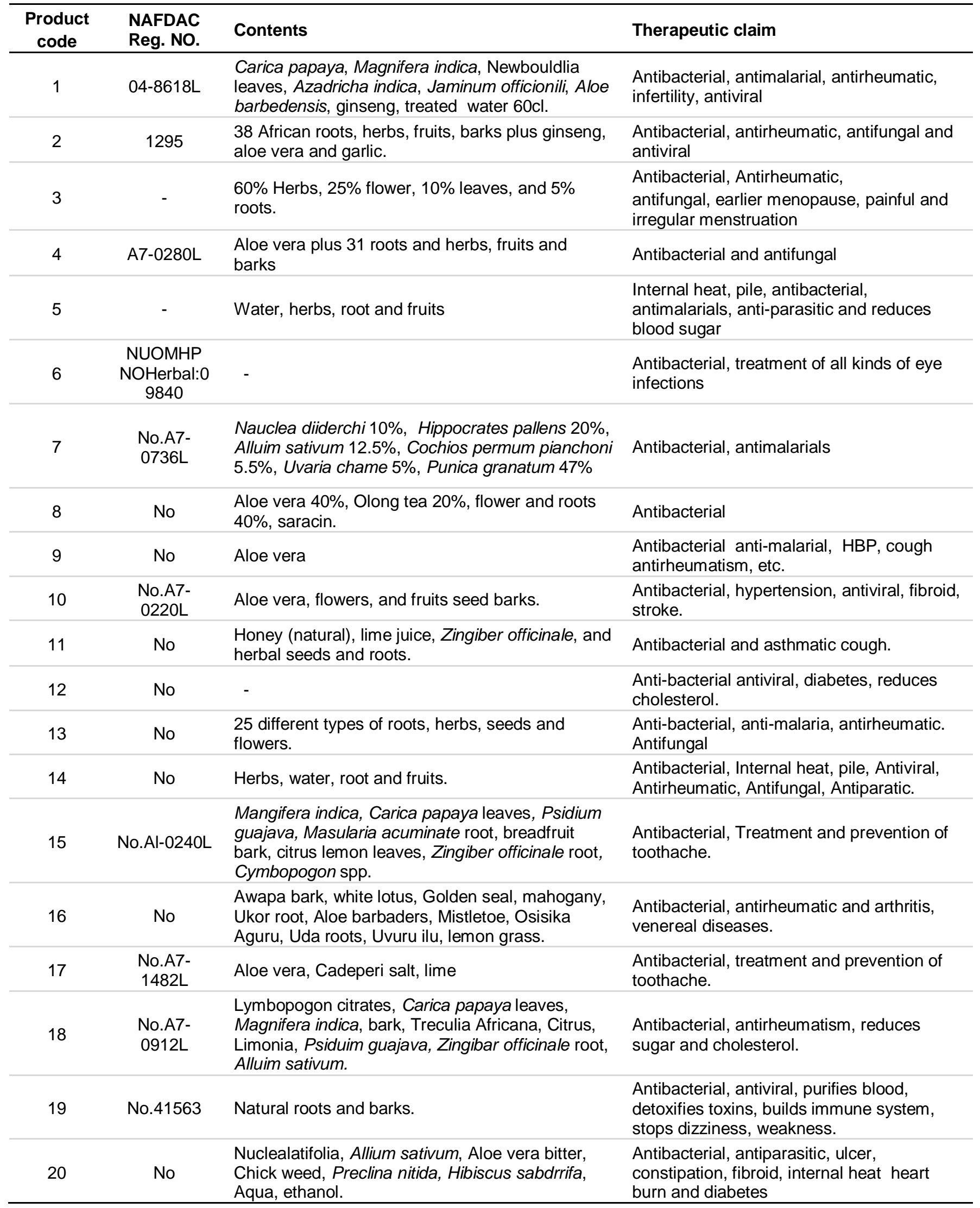


inoculums of the test microorganisms equivalent to $0.5 \mathrm{McF}$ arland were prepared and $0.1 \mathrm{ml}$ of the standard inoculum introduced into test tubes containing the dilutions of the herbal products. The tubes were incubated aerobically at $37^{\circ} \mathrm{C}$ for $24 \mathrm{~h}$. After $24 \mathrm{~h}$ a loopful of the different concentration were taken from the tubes and streaked on agar plates, which were also incubated at $37^{\circ} \mathrm{C}$ for $24 \mathrm{~h}$ after which the presence or absence of growth was observed and matched with the particular concentration. The highest dilution (lowest Concentration) of the agent that produced no visible bacterial growth when compared with the control plate was regarded as the MID.

Determination of the antimicrobial activity of the products against MRSA and ESBL- expressing E. coli and Klebsiella species

About $0.1 \mathrm{ml}$ of the standardized suspension (equivalent to 0.5 McFarland) of MRSA, ESBL expressing Escherichia coli and Klebsiella were obtained from the stock available in pharmaceutical and biotechnology lab, Faculty of Pharmacy, Nnamdi Azikiwe University, Agulu campus and aseptically transferred into labeled sterile Petri dishes. Then $20 \mathrm{ml}$ of molten sterile nutrient agar was poured into the seeded Petri dishes and swirled to distribute the medium homogenously. After solidification, holes were made aseptically with a $6 \mathrm{~mm}$ sterile cork borer and $1 \mathrm{ml}$ of the test solution of different concentrations introduced into the wells. The agents were allowed to diffuse into the medium and then incubated aerobically for 18 to $24 \mathrm{~h}$ at $37^{\circ} \mathrm{C}$. The plates were examined for zones of inhibition, which indicate the degree of susceptibility of the test organisms. The antimicrobial activity of the various agents was measured with a meter rule and compared with the control well (containing water).

\section{Determination of the level of microbial contamination of the products}

Exactly $1 \mathrm{ml}$ of each herbal anti-infectives was aseptically transferred into a corresponding sterile test tube containing $9 \mathrm{ml}$ of sterile distilled water and ten-fold serial dilution was carried out. Using the Pour plate technique, $1 \mathrm{ml}$ of dilutions $10^{-1}, 10^{-2} 10^{-3}, 10^{-4}$, and $10^{-5}$ were transferred to clean sterilized Petri dishes and mixed with $20 \mathrm{ml}$ of sterile molten nutrient agar and Sabouraud Dextrose agar which was cooled to $45^{\circ} \mathrm{C}$ for bacteria and fungi, respectively. These were done in triplicates and the plates were allowed to set and then incubated at $37^{\circ} \mathrm{C}$ for bacterial counts from 18 to $24 \mathrm{~h}$, and 20 to $27^{\circ} \mathrm{C}$ for fungal count for 72 to $168 \mathrm{~h}$. All counts were expressed in CFU/ml.

\section{Statistical analyses}

Analysis of variance (ANOVA) was performed to determine statistical significant differences in inhibition zone diameter (IZD) amongst the herbal products and the conventional antibiotics. The level of significance was set at 0.05 .

\section{RESULTS}

Table 1 shows the different liquid herbal anti-infectives that were evaluated in this work. All the products (100\%) had antibacterial claims, $6(30 \%)$ claimed to have antifungal activity while $13(65 \%)$ claimed to be effective for the management of non-infectious diseases/ conditions. None of the products investigated demonstrated any antifungal activity and only $40 \%$ of the products showed some antibacterial activity.

The antimicrobial activity of the herbal anti-infectives was evaluated against selected pathogenic bacteria and fungi as presented in Table 2 using agar well diffusion method. The table revealed that none of the herbal samples has antifungal effect, 3 out of the 20 inhibited the growth of $S$. aureus, with product 2 stock having the highest zone of inhibition $(26 \mathrm{~mm})$ and product 11 stock having the least $(16 \mathrm{~mm})$. Three of the herbal product inhibited the growth of Salmonella typhi with product 3 and 17 having a higher zone of inhibition of $12 \mathrm{~mm}$ than product 2 which has $10 \mathrm{~mm}$ IZD. The growth of $P$. aeruginosa was inhibited by 5 products. Product 2 had the highest IZD of $22 \mathrm{~mm}$ while products 5 and 9 have the least which is $10 \mathrm{~mm}$. Growth of $E$. coli was inhibited by two products; product 7 (IZD of $25 \mathrm{~mm}$ ) and product 11 (IZD of $14 \mathrm{~mm}$ ).

The bactericidal activity of the products ( $2,3,7$ and 11$)$ that showed significant antibacterial against at least two of the target bacteria was characterized using killing rate kinetics method (Table 3). The MID of the products that showed significant antibacterial activity against the test organisms is given in Table 4 and the activity of the herbal products against MRSA and ESBL expressing $E$. coli and Klebsiella is shown in Table 5. Table 6 shows the comparison of IZD of the herbal anti-infectives and conventional antibiotics. Table 7 shows the level of microbial contaminations of the products.

\section{DISCUSSION}

The herbal medicinal products selected for this study were all liquid dosage forms. Products $2,7,10,12$, and 17 were purchased from Aba in Abia state, products 1, 5, 6,9 , and 16 were from Anambra state, products 3, 4, 13, 18, 19, and 20 were from Ebonyi and Enugu States while Products 8, 14, and 15 were from Owerri in Imo State. All the samples were within their shelf-life at the time of investigation. Ten $(50 \%)$ of the products had NAFDAC registration number while the other $10(50 \%)$ were not registered by the agency. This is contrary to the laws governing the manufacture, advertisement, sale and distribution of herbal medicinal products and indeed all foods and drugs in Nigeria which forbids such when the products are not properly registered by NAFDAC (HMRP, 2004). The European Agency for the Evaluations of Medicinal Products (EAEMP) and WHO have stated that the quality of the herbal drug should be given as a range corresponding to a defined quantity of constituents with known therapeutic activity and if constituents responsible for therapeutic activity are unknown, the quantity of the whole herbal drug preparation should be given (EMEA, 2002; WHO, 1996a). They also stipulated that the dosage 
Table 2. Products' antimicrobial activity on the test organisms.

\begin{tabular}{|c|c|c|c|c|c|c|c|c|c|c|}
\hline \multirow{3}{*}{ Product } & \multicolumn{10}{|c|}{ IZD (mm) } \\
\hline & \multicolumn{2}{|c|}{ E. coli } & \multicolumn{2}{|c|}{$P$. aeruginosa } & \multicolumn{2}{|c|}{ S. aureus } & \multicolumn{2}{|c|}{ S. typhi } & \multicolumn{2}{|c|}{ C. albicans } \\
\hline & Stock & Dilution & Stock & Dilution & Stock & Dilution & Stock & Dilution & Stock & Dilution \\
\hline Product 1 & - & - & 18 & 18 & - & - & - & - & - & - \\
\hline Product 2 & - & - & 22 & 20 & 26 & 22 & 10 & 10 & - & - \\
\hline Product 3 & - & - & 16 & 16 & - & - & 12 & 12 & - & - \\
\hline Product 4 & - & - & - & - & - & - & - & - & - & - \\
\hline Product 5 & - & - & 10 & 10 & - & - & - & - & - & - \\
\hline Product 6 & - & - & - & - & - & - & - & - & - & - \\
\hline Product 7 & 25 & 18 & - & - & 18 & 18 & - & - & - & - \\
\hline Product 8 & - & - & - & - & - & - & - & - & - & - \\
\hline Product 9 & - & - & 10 & 10 & - & - & - & - & - & - \\
\hline Product 10 & - & - & - & - & - & - & - & - & - & - \\
\hline Product 11 & 14 & 12 & - & - & 16 & 12 & - & - & - & - \\
\hline Product 12 & - & - & - & - & - & - & - & - & - & - \\
\hline Product 13 & - & - & - & - & - & - & - & - & - & - \\
\hline Product 14 & - & - & - & - & - & - & - & - & - & - \\
\hline Product 15 & - & - & - & - & - & - & - & - & - & - \\
\hline Product 16 & - & - & - & - & - & - & - & - & - & - \\
\hline Product 17 & - & - & - & - & - & - & 12 & 12 & - & - \\
\hline Product 18 & - & - & - & - & - & - & - & - & - & - \\
\hline Product 19 & - & - & - & - & - & - & - & - & - & - \\
\hline Product 20 & - & - & - & - & - & - & - & - & - & - \\
\hline
\end{tabular}

$\mathrm{S}=$ Stock Concentration, D = Diluted Concentration (2-fold), - = No inhibition.

Table 3. Anti-bacterial activity of the products with significant activity using kill kinetic method.

\begin{tabular}{ccccccccccc}
\hline \multirow{2}{*}{$\begin{array}{c}\text { Time } \\
\text { (h) }\end{array}$} & \multicolumn{7}{c}{ Bacterial load (CFU/ml) } \\
\cline { 2 - 11 } & Prod. 2 & Prod. 3 & Prod. 7 & Prod. 2 & Prod. 7 & Prod.11 & Prod. 7 & Prod.11 & Prod. 2 & Prod. 3 \\
\hline 0 & 221 & 221 & 248 & 49 & 41 & 41 & 44 & 19 & 77 & 112 \\
1 & 209 & 202 & 236 & 37 & 19 & 29 & 24 & 22 & 56 & 95 \\
2 & 204 & 185 & 204 & 26 & 38 & 26 & 3 & 15 & 48 & 81 \\
3 & 180 & 179 & 146 & 20 & 56 & 20 & 0 & 12 & 44 & 66 \\
4 & 170 & 172 & 87 & 17 & 10 & 17 & 0 & 0 & 29 & 51 \\
5 & 162 & 162 & 51 & 0 & 0 & 10 & 0 & 0 & 19 & 39 \\
\hline
\end{tabular}

Prod.: Product.

Table 4. MID of the products with significant antibacterial activity.

\begin{tabular}{lcccc}
\hline \multirow{2}{*}{ Test organism } & \multicolumn{4}{c}{ MID of the products $(\% \mathbf{~ v / v ) ~}$} \\
\cline { 2 - 5 } & Product 2 & Product 3 & Product 7 & Product 11 \\
\hline S. typhi & 66.6 & 25 & 66.6 & - \\
P. aeruginosa & 66.6 & 66.6 & - & - \\
S. aureus & 150 & - & 66.6 & 150 \\
E. coli & - & - & 66.6 & 150 \\
\hline
\end{tabular}

form, therapeutic indications and expiry dates should be stated. However, $3(15 \%)$ of the products did not have their content stated even though therapeutic claims were indicated either on the container or in the leaflet insert. 
Table 5. Antibiotic activity of the products against MRSA and ESBL-Expressing Organisms.

\begin{tabular}{ccccccccc}
\hline \multirow{2}{*}{ Product } & \multicolumn{2}{c}{ MRSA 1 } & \multicolumn{2}{c}{ MRSA 2 } & \multicolumn{2}{c}{ ESBL (E. coll) } & \multicolumn{2}{c}{ ESBL (Klebsiella) } \\
\cline { 2 - 9 } & Stock & Dilution & Stock & Dilution & Stock & Dilution & Stock & Dilution \\
\hline 2 & - & - & - & - & - & - & - & - \\
3 & - & - & - & - & - & - & - & - \\
7 & 30 & 27 & 13 & 13 & - & - & - & - \\
11 & - & - & - & - & - & - & - & - \\
\hline
\end{tabular}

MRSA: Methicillin Resistant Staphylococcus aureus; ESBL: Extended Spectrum Beta-Lactamase; Dilution: Two-fold dilution; -: No inhibition.

Table 6. Inhibition Zone Diameter $(\mathrm{mm})$ of the products and conventional antibiotics.

\begin{tabular}{lcccccccccc}
\hline Test organism & P 2 & P 3 & P 5 & P 7 & P 11 & OFX & CIP & TE & GN & CRO \\
\hline S. typhi & 10 & 26 & - & 24 & - & 15 & 32 & 14 & 26 & - \\
P. aeruginosa & 22 & 16 & 10 & - & - & - & 17 & - & 20 & 16 \\
S. aureus & 26 & - & - & 18 & 16 & 25 & 20 & 8 & - & 13 \\
E. coli & - & - & - & 18 & 14 & - & 15 & - & 16 & - \\
\hline
\end{tabular}

P: Product; OFX: ofloxacin; CIP: ciprofloxacin; CAZ: ceftazidime; TE: tetracycline; AMP: ampicillin; SXT: sulfamethoxazole-trimethoprim; GN: gentamicin; CTX: cefotaxime; CRO: ceftriaxone; AMC: amoxycillin-clavulanic acid.

Table 7. Level of microbial contamination of the products.

\begin{tabular}{ccccccccc}
\hline Product & \multicolumn{9}{c}{ Bacterial } & count (CFU/mI) & \multicolumn{4}{c}{ Fungal count (CFU/mI) } \\
\cline { 2 - 8 } code & Plate1 & Plate 2 & Plate 3 & $\dot{\mathbf{X}} \pm$ SEM & Plate 1 & Plate 2 & Plate 3 & X \pm SEM \\
\hline 1 & 28 & 35 & 23 & $2.9 \times 10^{3} \pm 3.48$ & 5 & 7 & 3 & $5 \times 10^{4} \pm 1.15$ \\
2 & 27 & 38 & 30 & $3.2 \times 10^{2} \pm 3.28$ & 4 & 3 & 5 & $4 \times 10^{4} \pm 0.58$ \\
3 & 36 & 48 & 50 & $4.5 \times 10^{4} \pm 4.37$ & 9 & 4 & 2 & $5 \times 10^{5} \pm 2.08$ \\
4 & 35 & 40 & 42 & $3.9 \times 10^{3} \pm 2.08$ & 7 & 12 & 4 & $8 \times 10^{3} \pm 2.33$ \\
5 & 90 & 73 & 67 & $7.7 \times 10^{2} \pm 6.89$ & 0 & 0 & 0 & - \\
6 & 28 & 47 & 32 & $3.6 \times 10^{3} \pm 5.78$ & 16 & 2 & 1 & $6 \times 10^{2} \pm 4.84$ \\
7 & 7 & 7 & 7 & $7 \times 10^{1} \pm 0.00$ & 46 & 20 & 26 & $3.1 \times 10^{3} \pm 7.86$ \\
8 & 4 & 51 & 10 & $2.2 \times 10^{4} \pm 14.77$ & 30 & 32 & 28 & $3.0 \times 10^{3} \pm 1.15$ \\
9 & 25 & 92 & 15 & $4.4 \times 10^{3} \pm 24.17$ & 35 & 18 & 17 & $2.3 \times 10^{2} \pm 5.84$ \\
10 & 76 & 67 & 60 & $6.8 \times 10^{4} \pm 4.63$ & 25 & 25 & 20 & $2.3 \times 10^{4} \pm 1.67$ \\
11 & 250 & 250 & 200 & $2.33 \times 10^{6} \pm 16.67$ & 30 & 25 & 5 & $2.0 \times 10^{3} \pm 7.64$ \\
12 & 116 & 120 & 100 & $1.12 \times 10^{5} \pm 6.11$ & 94 & 90 & 94 & $9.4 \times 10^{5} \pm 1.33$ \\
13 & 48 & 35 & 40 & $4.1 \times 10^{5} \pm 3.79$ & 30 & 38 & 40 & $3.6 \times 10^{3} \pm 3.06$ \\
14 & 93 & 62 & 70 & $7.5 \times 10^{3} \pm 9.29$ & 30 & 36 & 32 & $3.3 \times 10^{4} \pm 1.76$ \\
15 & 41 & 45 & 40 & $4.2 \times 10^{3} \pm 1.53$ & 35 & 30 & 15 & $2.7 \times 10^{5} \pm 6.01$ \\
16 & 64 & 55 & 68 & $6.2 \times 10^{3} \pm 3.84$ & 40 & 41 & 39 & $4.0 \times 10^{5} \pm 0.58$ \\
17 & 48 & 50 & 45 & $4.8 \times 10^{3} \pm 1.45$ & 50 & 49 & 51 & $5.0 \times 10^{5} \pm 0.58$ \\
18 & 109 & 100 & 98 & $1.02 \times 10^{6} \pm 3.38$ & 10 & 15 & 11 & $1.2 \times 10^{5} \pm 1.53$ \\
19 & 15 & 20 & 30 & $2.2 \times 10^{2} \pm 4.41$ & 55 & 50 & 56 & $5.4 \times 10^{4} \pm 1.86$ \\
20 & 46 & 40 & 38 & $4.1 \times 10^{4} \pm 2.40$ & 12 & 12 & 12 & $1.2 \times 10^{2} \pm 0.00$ \\
\hline
\end{tabular}

All the products (100\%) had antibacterial claims, $6(30 \%)$ claimed to have antifungal activity while $13(65 \%)$ claimed to be effective for the management of noninfectious diseases/conditions. Medicinal products designed for the purpose of chemotherapeutic and pharmacological benefits should be effective against the target medical condition.

The evaluation of the antimicrobial activity of the products against test organisms ( $S$. aureus, E. coli, $S$. typhi, $P$. aeruginosa and $C$. albicans) (Table 2) showed 
that only $8(40 \%)$ of the herbal products (products $1,2,3$, $5,7,9,11$, and 17) have some antibacterial activity. Four out of the eight products showed significant activity. None of the products showed antifungal activity against the test fungi organism even though six $(30 \%)$ of the products $(2$, $3,4,10,13$, and 14) claimed to have antifungal activity. The poor antimicrobial activity as shown by the herbal products against the test organisms could be attributed to the fact that the products were contaminated as shown in Table 7. The presence of microbial contaminants in nonsterile pharmaceutical products can reduce or even inactivate the therapeutic activity of the product and has the potential to adversely affect patients taking the medicines (Nakajima et al., 2005; Okunlola et al., 2007). Apart from possible microbial degradation of the active constituents contained in the herbal preparations, the presence of these contaminating microorganisms could constitute a source of infection and serious health risk to the consumers of the herbal preparations who were probably already overwhelmed by the serious medical conditions for which the herbal drugs were initially indicated (Mangram et al., 1999; Bowler et al., 2001). Spoilage of medicines involve initial or pioneer invading biodegrading microorganisms, which prepare the way for later invaders that biodegrade complex nutrient, thus altering the surrounding $\mathrm{pH}$ and increasing moisture content (Omwuliri and Wonang, 2005). On the other hand, the anti-microbial claims of the products may not be true.

Further evaluation on the bactericidal action of the herbal products with significant antibacterial activity was done using kill kinetic method. The herbal preparations showed bactericidal effect on the indicator bacteria as bacterial load decreased from the first hour to the fifth hour (Table 3). Product 7 seems to have erratic effect on $S$. typhi. The organism was not very susceptible to the products generally. E. coli was found to be susceptible to antibacterial actions of herbal preparations 7 and $11, S$. aureus was found to be susceptible to the antibacterial actions of products 2 and 7 but less to product 11 . Susceptibility of $P$. aeruginosa to the products 2 and 3 was also observed as the products were able to reduce the bacteria load significantly although more time was observably needed to clear the organisms. The MID of the herbal products that showed significant antibacterial activity was also evaluated (Table 4), and the result showed that at higher dilutions, the products have little or no antibacterial activity. Evaluation of the actions of the products against MRSA and ESBL expressing E. coli and Klebsiella spp. (Table 5) revealed that only one of the products (Product 7) showed activity against MRSA and none had activity against ESBL-expressing organisms. This shows that in cases of infections caused by these organisms, the products are powerless.

In the present study, it was observed that herbal products were grossly contaminated by fungal and bacterial agents, with the exception of one that was not contaminated with fungi (Product 5) (Table 7). Contami- nation by microorganisms is influenced by the environment, improper handling and storage of medicinal plants (Idu et al., 2010; Oleghe et al., 2011). Herbal medicinal plants usually contain bacteria and molds from soil and atmosphere. Microorganisms are everywhere. This can be supported by the results of the present research as the herbal products from all the five states were all contaminated. One of the major shortcomings of herbal preparations in developing countries is the unhygienic condition under which they are produced (Frazier and Westhoff, 2003).

From the ANOVA, the comparison of the herbal products with conventional antibiotic shows no significant difference. This suggests that both the herbal products and the antibiotics have the potential to produce antibacterial effect (Table 6), but aseptic techniques may not have been applied during the manufacture of the products. Some studies on the sterility of the manufacturing environment of these companies are hereby suggested.

\section{Conclusion}

Only $40 \%$ of the 20 products have some antibacterial activity, but none have anti-fungal activity. All were heavily contaminated with microorganisms. Current good manufacturing practice may not have been applied in their manufacture.

\section{ABBREVIATIONS}

EAEMP, The European Agency for the Evaluations of Medicinal Products; EMEA, European Medicines Evaluation Agency; NAFDAC, National Agency for Food Drug Administration and Control; HMRP, Herbal Medicines and Related Products; MRSA, methicillin resistant Staphylococcus aureus; ESBL, extended spectrum beta-Lactamase; HMPWP, Herbal Medicinal Products Working Party.

\section{REFERENCES}

Barkatullah BB, Muahmmad I, Niaz A, Naveed M, Rehmanullah (2013). Antispasmodic potential of leaves barks and fruits of Zanthoxylum armatum DC. Afri. J.Pharm. Pharmacol. Vol. 7(13):pp. 685-693

Bauer R (1998). Quality criteria and standardization of phytopharmaceuticals: Can acceptable drugs standard be achieved? Drugs Inform. J. 32:101-110.

Bodeker C, Bodeker G, Ong CK, Grundy CK, Burford G, Shein K (2005). WHO Global Atlas of Traditional, Complementary and Alternative Medicine. World Health Organization, Geneva.

Bowler PG, Duerden BI, Armstrong DG (2001). Wound microbiology and associated approaches to wound management. Clin. Microbiol. Rev. 14(2):244-269.

Eisenberg D, David RB, Ettner SL, Appel S, Van Rompay M, Kessler RC (1998). Trends in alternative medicine use in the United States, 1990 - 1997; JAMA 280:1569-1575.

EMEA (2002). Points to Consider on Good Agricultural and Collection Practice for Starting Materials of Herbal Origin; EMEA/HMPWP/31/99 Review: European Agency for the Evaluation of Medicinal Products (EMEA), London PP 1-13. 
Esimone CO, Chah KF, Ikejide SC (2002). Microbiological quality of herbal preparations marketed in Southeast Nigeria. J. Nat. Remedies 2:42-48

Evans WC (1996). Trease and Evans Pharmacognosy 14th Edn WB Saunders Ltd, London. pp 119-159.

Kunle OF, Egharevba HO, Ahmadu PO (2012). Standardization of herbal medicines. Int. J. Biodiv. Conserv. Vol. 4(3):101-112

Frazier WC, Westhoff DC (2003). Food Microbiology, London: Mc-Graw Hill Publishing Company Limited, pp 1200-1202.

Herbal Medicines and Related Products (Registration) Regulations (2004): www.nafdacnigeria.org/newregs/regulations.html. Last accessed on October 10, 2006

Idu M, Omonigbo SE, Erhaborland JO, Efijuemuel HM (2010). Microbial Load of Some Medicinal Plants Sold in Some Local Markets In Abeokuta, Nigeria: Trop. J. Pharm. Res. 9(3):251-256.

Langyan NK, Ahuja M (2005). Estimation of nickel and cobalt in herbal product:, In:141st British Pharmaceutical Conference Science proceedings. p 220.

Mangram AJ, Horan TC, Pearson ML, Silver LC, Jarvis WR (1999). Guideline for prevention of surgical site infection. Am. J. Infect. Control 27:97-134.

Monica C (2002). District Laboratory Practice in Tropical Countries (Part 2); Cambridge University Press. PP 62-70.

Mosihuzzaman M, Choudhary MI (2008). Protocols on Safety, Efficacy, Standardization and Documentation of Herbal Medicine: International Union of Pure and Applied Chemistry (IUPAC Technical Report). Pure Appl. Chem. Vol. 80, No. 10, pp. 2195-2230.

Mukherjee PW (2002). Quality Control of Herbal Drugs: An Approach to Evaluation of Botanicals; Business Horizons Publishers, New Delhi, India.

Nakajima K, Nonaka K, Yamamoto K, Yamaguchi N, Tani K, Nasu M (2005). Rapid monitoring of microbial contamination on herbal medicines by fluorescent staining method. Lett. Appl. Microbiol. 40(2):128-132

Ogunshe AAO, Fasola TR, Egunyomi A (2006). Bacterial profiles and consumer preference of some indigenous orally consumed herbal medications in Nigeria. J. Rural Trop. Pub. Health 5:27-33.

Okunade AO (2001). The under development of health care system in Nigeria, Faculty of Clinical Sciences and Dentistry, University of Ibadan; Vantage publishers Ltd Ibadan, Nigeria. p.43

Okunlola A, Adewoyin AB, Odeku AO (2007). Evaluation of pharmaceutical and microbial qualities of some herbal medicinal products in south western Nigeria. Trop. J. Pharm. Res. 6(1):661670 .
Oleghe PO, Odimegwu DC, Udofia E, Esimone CO (2011). Multi-DrugResistant Bacteria Isolates Recovered from Herbal Medicinal Preparations an a Southern Nigerian Setting. J. Rural Trop. Pub. Health Vol 10: p. 70-75.

Oluyege JO, Adelabu DM (2010). Microbial Contamination of Some Hawked Herbal Products in Ado-Ekiti, Nigeria. Continental Microbiol. 4:8-14

Omwuliri FC, Wonang DL (2005). Studies on the combined antibacterial action of ginger (Zingiber officinale L.) and garlic (Allium sativum L.) on some bacteria. Nig. J. Botany 18:224-228.

Rios JL, Recio MC (2005). Medicinal plants and antimicrobial activity. J. Ethnopharmacol.100:80-84.

Samy AS, Mohamed HAA, Mona SM, Mona FW (2013). Antibacterial activities, chemical constitutes and acute toxicity of Egyptian Origanum majorana L., Peganum harmala $L$. and Salvia officinalis $L$. essential oils. Afr. J. Pharm. Pharmacol. Vol. 7(13):pp. 725-735.

Sofowora A (1993). Medicinal plants and Traditional medicine in Africa, Ibadan: Spectrum books Ltd (pub); pp. 50-195

Vanderhoof JA (2001). Probiotics: future directions. Annals J. Clin. Nut. 73:1152S-1155S.

WHO (1996a). Expert Committee on Specifications for Pharmaceutical Preparations: Thirty-fourth report. Geneva, (WHO Technical Report Series No. 863, thirty-fourth report, pp.178-184), 60

Wilt TJ, Ishani A, Rutks I, MacDonald R (2000). Phytotherapy for benign prostatic hyperplasia. Pub. Health Nut. 3:459-472. 